\title{
PENGARUH ADULT ATTACHMENT TERHADAP STRATEGI REGULASI EMOSI PADA MAHASISWA PERANTAU DI UNIVERSITAS X
}

\author{
Krishervina R. Lidiawati ${ }^{1}$, Tanya Fransisca ${ }^{2}$ \\ Universitas Pelita Harapan ${ }^{1,2}$, Tangerang, Indonesia \\ Email: krishervina.lidiawati@uph.edu ${ }^{1}$,tanya28fransisca@gmail.com ${ }^{2}$
}

\begin{abstract}
This study will examine the effect of adult attachment on the emotional regulation strategy of overseas students at X University. This research is a quantitative study with sampling using purposive sampling technique. The number of participants in this study were 167 overseas students who came from outside Jabodetabek at University X (121 female and 46 male). Participants age from 18-25 years. The measuring instrument used is the ECR-R-GSF for adult attachments and ERQ for emotional regulation strategies. Data analysis used multiple regression with SPSS 23.0 application. The results obtained showed that there was an effect of adult attachment on expressive suppression with the avoidance dimension which had a significant effect ( $p=.000, p<.05)$ of $13.5 \%$ and the anxiety dimension had no significant effect $(p=.054, p>$. 05). Other results found no effect of adult attachment on cognitive reappraisal.
\end{abstract}

Keywords: Overseas Students; Adult Attachment; Emotion Regulation Strategy

\begin{abstract}
ABSTRAK
Penelitian ini akan meneliti pengaruh dari adult attachment terhadap strategi regulasi emosi pada mahasiswa perantau di Universitas X. Penelitian ini adalah penelitian kuantitatif dengan pengambilan sampel menggunakan teknik purposive sampling. Jumlah partisipan dalam penelitian ini adalah 167 mahasiswa perantau yang berasal dari luar Jabodetabek di Universitas X (121 Perempuan dan 46 Laki-laki). Usia partisipan dari 18-25 tahun. Alat ukur yang digunakan adalah ECR-R-GSF untuk adult attachment dan ERQ untuk strategi regulasi emosi. Analisis data mengguunakan regresi berganda dengan aplikasi SPSS 23.0. Hasil yang didapatkan menunjukkan ada pengaruh dari adult attachment terhadap expressive suppression dengan dimensi avoidance yang memberikan pengaruh secara signifikan $(p=.000, p<.05)$ sebesar $13.5 \%$ dan dimensi anxiety tidak berpengaruh secara signifikan $(p=.054, p>.05)$. Hasil lainnya tidak ditemukan pengaruh dari adult attachment terhadap cognitive reappraisal.
\end{abstract}

Kata kunci: Mahasiswa Perantau; Adult Attachmnet; Strategi Regulasi Emosi 


\section{PENDAHULUAN}

Tahun 2017 tercatat jumlah warga Indonesia yang sedang menempuh pendidikan tinggi berjumlah 6.924.511 juta jiwa (Kementerian Riset, Teknologi, dan Pendidikan Tinggi [Kemenristekdikti], 2017). Berdasarkan persebaran mahasiswa yang ada di Indonesia, pulau Jawa menempati urutan pertama dengan jumlah mahasiswa sebesar 3.958.577 juta jiwa (Kemenristekdikti, 2017). Rufaida dan Kustanti (2017) menyebutkan bahwa pulau Jawa menjadi salah satu tujuan mahasiswa yang berasal dari daerah lain untuk melanjutkan pendidikan tinggi karena lebih banyak pilihan universitas unggulan di pulau Jawa. Individu yang pergi ke negara lain atau daerah lain untuk mencari penghidupan, ilmu dan sebagainya disebut sebagai perantau (Kamus Besar Bahasa Indonesia [KBBI], 2008). Individu dalam konteks penelitian ini adalah mahasiswa sehingga akan disebut sebagai mahasiswa perantau karena pergi ke daerah lain untuk mencari ilmu dalam bentuk melanjutkan pendidikan tinggi.

Mahasiswa yang pergi ke daerah lain atau merantau tentunya akan menghadapi berbagai perubahan dan perbedaan dalam kehidupannya (Rufaida \& Kustanti, 2017). Perbedaan pola hidup, kebiasaan, interaksi sosial, bahasa, pertemanan, akademik menjadi hal yang akan dihadapi oleh mahasiswa yang merantau (Ridha, 2018; Perry, 2016). Mahasiswa perantau ketika menghadapi tantangan tersebut juga memunculkan emosi, salah satunya adalah emosi negatif. American College Health Association (dalam Altinyelken, 2018) menunjukkan surveinya terhadap emosi yang dirasakan mahasiswa perantau selama dua minggu dan hasilnya adalah mahasiswa merasa tidak ada harapan, kelelahan, sendirian, sedih, depresi, dan cemas.

Emosi negatif ini bisa menjadi masalah dan tekanan bagi mahasiswa perantau jika tidak diatasi, seperti yang dikatakan oleh Benvenuto (dalam Anggraini, 2015) bahwa emosi negatif bisa memengaruhi aktivitas sehari-hari seseorang. Salah satu hal yang bisa membantu mahasiswa perantau menghadapi berbagai hal tersebut adalah dengan regulasi emosi, seperti yang juga dikatakan oleh Anggraini (2015) bahwa regulasi emosi bisa membantu agar bisa tetap efektif dan adaptif dalam menghadapi tekanan.

\section{Strategi Regulasi Emosi}

Thompson (dalam Ahmetoglu, Ildis, Acar, Ibrahim, \& Encinger, 2018) menjelaskan regulasi emosi sebagai sebuah proses internal dan eksternal yang ada dalam diri seseorang dan bertanggung jawab dalam hal memonitoring, menilai dan juga memodifikasi emosi. Gross dan John (2003) menjelaskan ada dua strategi dalam meregulasi emosi, yaitu cognitive reappraisal dan expressive suppression. Cognitive reappraisal adalah strategi regulasi emosi yang akan menginterpretasi ulang emosi yang berhubungan dengan suatu situasi dan tujuannya adalah untuk mengubah dampak dari emosi tersebut (Gross \& John, dalam Ong \& Thompson, 2018). Strategi berikutnya adalah expressive suppression, ini adalah strategi yang menyembunyikan atau mengurangi emosi yang dirasakan. (Gross \& John, dalam Ong \& Thompson, 2018).

\section{Adult Attachment}

Attachment sendiri adalah sebuah ikatan emosi yang penting, kuat dan bermakna antara seseorang dengan orang lain (Bowlby, dalam Ahmetoglu et al., 2018). Hazar dan Shaver (dalam Bartholomew, Kwong, \& Hard, 2001) menjelaskan bahwa ada dua macam dimensi dalam adult attachment, yaitu dimensi anxiety dan dimensi avoidance. Hepper dan Carnelley (2012) memberikan penjelasan bahwa dimensi anxiety merujuk kepada individu yang takut akan penolakan, dibuang dan tidak dianggap dalam suatu hubungan. Pada akhirnya individu dengan dimensi anxiety akan melakukan hyper-activated attachment yang adalah melebih-lebihkan sesuatu agar mendapatkan perhatian dari figur attachment (Shaver \& 
Mikulincer, 2002; Hepper \& Carnelley, 2012). Dimensi avoidance merujuk kepada individu yang menghindari hubungan yang intim, tidak suka bergantung kepada orang lain dan cenderung sangat mandiri (Hepper \& Carnelley, 2012). Dimensi avoidance ini akan membuat individu melakukan deactivated attachment (Shaver \& Mikulincer, 2002; Hepper \& Carnelley, 2012).

Bartholomew (Otani, dkk., 2015) menjelaskan mengenai model of self dikaitkan dengan dimensi anxiety yang melihat cara individu memandang dirinya sendiri, apakah berharga dan kompeten. Jika dimensi anxiety pada diri individu tinggi maka model of self akan bersifat negatif yang membuat individu merasa tidak mampu dan nantinya akan bergantung pada orang lain. Model of other dikaitkan dengan dimensi avoidance yang melihat cara individu memandang orang lain apakah bisa dipercaya dan dapat diandalkan, jika dimensi avoidance tinggi maka model of other akan bersifat negatif. Individu akan melihat orang lain tidak bisa diandalkan dan tidak bisa dipercaya, sehingga akan cenderung menarik diri atau menghindari bergantung kepada orang lain (Bartholomew, dalam Otani, dkk., 2015).

\section{Adult Attachment dan Strategi Regulasi Emosi}

Jika dihubungkan dengan regulasi emosi, maka individu juga akan meregulasi emosi sesuai dengan internal working model. Individu yang memiliki dimensi avoidance yang tinggi, berarti individu mempunyai model of other yang negatif. Individu akan menganggap bahwa tidak ada figur attachment yang ada saat dibutuhkan, akhirnya menghindari emosi negatif dan tidak menyadari emosi itu sendiri (Mikulincer \& Shaver, 2007). Individu akan menghambat emosi yang bersifat negatif karena dianggap mengancam, tidak sesuai dengan tujuan dan akhirnya menonaktifkan sistem attachment (Mikulincer \& Shaver, 2007).

Mikulincer dan Shaver (2007) menemukan bahwa dimensi avoidance yang tinggi mempunyai hubungan dengan penggunaan expressive suppression dan tidak bisa secara efektif menggunakan cognitive reappraisal. Penelitian yang sama juga dilakukan Read et al. (2018) yang menemukan hubungan dimensi avoidance dengan expressive suppression lebih tinggi dibandingkan dimensi anxiety dengan expressive suppression.

Individu yang mempunyai dimensi anxiety yang tinggi akan melihat emosi negatif sebagai sesuatu yang sesuai dengan tujuan dalam attachment (Mikulincer \& Shaver, 2007). Individu akan fokus pada emosi yang negatif dan justru akan melebih-lebihkan masalah. Cara mengaktivasi sistem attachment dilakukan secara berlebihan dan bisa berakhir dengan tidak bisa lepas dari lingkaran masalah walaupun pada kenyataanya masalahnya sudah selesai (Mikulincer \& Shaver, 2007; Pascuzzo et al., 2015). Hal itu dilakukan karena individu mempunyai model of self yang negatif, individu akan merasa tidak berdaya (Read et al., 2018).

Pascuzzo et al. (2015) dalam penelitiannya tentang attachment dan strategi regulasi emosi menyebutkan bahwa individu dengan dimensi anxiety yang tinggi akan melakukan hal demikian agar terus mendapatkan perhatian dari figur attachment. Mikulincer dan Shaver (2007) mengatakan bahwa dimensi anxiety yang tinggi biasanya diasosiasikan dengan ketidakmampuan menggunakan cognitive reappraisal yang efektif. Hal ini juga sejalan dengan penelitian Read et al. (2018) yang menemukan bahwa cognitive reappraisal memiliki hubungan yang negatif dengan dimensi anxiety dan dimensi avoidance.

Berdasarkan penelitian di atas bisa dilihat bahwa memang ada hubungan antara dimensi attachment dengan strategi regulasi, terkhususnya dalam penelitian ini adalah mahasiswa perantau. Masuknya mahasiswa perantau ke dunia perkuliahan di lingkungan baru bisa diasosiasikan sebagai strange situation yang membuat mahasiswa perantau harus mengeksplorasi lingkungan baru tersebut (Kural \& Ozyurt, 2018). Saat mahasiswa perantau mengeksplorasi lingkungan baru, mahasiswa perantau bisa menghadapi tantangan dan hal 
yang menekan. Pada saat itulah sistem attachment diaktifkan dan mahasiswa perantau mencari dukungan dari figur attachment (Kural \& Ozyurt, 2018).

Jika mahasiswa perantau punya pandangan ada figur attachment yang bisa diandalkan maka mahasiswa perantau akan bisa meregulasi emosi dengan strategi regulasi emosi yang lebih efektif, namun jika tidak ada maka mahasiswa perantau akan mengalami kendala dalam meregulasi emosi.

Pada penelitian kali ini peneliti ingin melihat pengaruh dari attachment tersebut kepada strategi regulasi emosi pada mahasiswa perantau karena penelitian sebelumnya banyak dilakukan pada individu dewasa ataupun dewasa muda yang sedang menjalin hubungan romantis. Mahasiswa perantau termasuk dalam dewasa muda, namun tidak semua mahasiswa perantau sedang menjalin hubungan romantis sehingga attachment yang diukur pada penelitian ini lebih bersifat umum dan tidak pada satu figur attachment spesifik. Mahasiswa perantau juga mempunyai tantangan tersendiri di tempat rantaunya terlebih lagi harus terpisah jarak mungkin dengan figur attachmentnya dan membangun hubungan baru lagi dengan orang baru.

Penelitian ini mengambil sampel dari mahasiswa perantau di Universitas X. Peneliti memilih Universitas X karena Universitas X mempunyai jumlah mahasiswa perantau yang cukup banyak. Data dari bagian administrasi Universitas $\mathrm{X}$ ditemukan jumlah keseluruhan mahasiswa adalah sejumlah 12.021 dan ada sejumlah 6.546 adalah mahasiswa perantau. Hal ini menunjukkan bahwa lebih dari 50\% mahasiswa Universitas X adalah mahasiswa perantau. Mahasiswa perantau di Universitas X juga memiliki masalah-masalah yang dialami di tempat perantauannya. Masalah atau tantangan tersebut secara frekuensi juga sering di alami oleh mahasiswa perantau. Mahasiswa perantau di Universitas X sebanyak 50\% lebih juga menyatakan bahwa masalah-masalah tersebut sering dialami dan berdasarkan survei mahasiswa perantau juga merasa terganggu dengan masalah tersebut.

Hal-hal tersebutlah yang akhirnya membuat peneliti ingin meneliti pengaruh dari adult attachment terhadap strategi regulasi emosi pada mahasiswa perantau di Universitas X. Hipotesis dari penelitian ini, yaitu:

$\mathrm{H}_{1} \quad$ : Tidak terdapat pengaruh dimensi attachment anxiety dan avoidance terhadap cognitive reappraisal.

$\mathrm{H} 1_{1}$ : Terdapat pengaruh dimensi attachment anxiety dan avoidance terhadap cognitive reappraisal.

$\mathrm{HO}_{2}$ : Tidak terdapat pengaruh dimensi attachment anxiety dan avoidance terhadap expressive suppression.

$\mathrm{H}_{2}$ : Terdapat pengaruh dimensi attachment anxiety dan avoidance terhadap expressive suppression.

\section{METODE}

\section{Partisipan}

Jumlah partisipan dalam penelitian ini adalah 167 mahasiswa perantau yang berasal dari luar Jabodetabek di Universitas X (121 Perempuan dan 46 Laki-laki). Usia partisipan dari 18-25 tahun. Teknik pengambilan sampel menggunakan purposive sampling.

\section{Desain Penelitian}

Penelitian ini menggunakan metode kuantitatif non-experimental. Kuantitatif adalah metode yang mengukur variabel untuk mendapatkan hasil berupa angka-angka dan kemudian akan dianalisis memakai teknik statistik (Gravetter \& Forzano, 2012). Penelitian ini juga merupakan penelitian non-experimental karena tidak ada manipulasi dan mengontrol variabel. 
Penelitian ini memakai pendekatan cross-sectional yang hanya melakukan pengambilan data sekali (Gravetter \& Forzano, 2012).

\section{Prosedur}

Partisipan yang sudah bersedia ikut dalam penelitian diberikan lembar informed consent terlebih dahulu untuk diisi dan kemudian partisipan akan mengisi kuesioner alat ukur dalam bentuk hardcopy. Pengisian kuesioner membutuhkan waktu 5 sampai 10 menit.

\section{Teknik Analisis}

Analisis data menggunakan bantuan dari SPSS 23.0 for windows. Teknik analisis yang dipakai ada uji asumsi klasik, uji korelasi menggunakan Spearman's Rho karena data tidak normal, kemudian uji regresi berganda dan uji beda menggunakan Mann Whitney dan Kruskal Wallis.

\section{HASIL DAN PEMBAHASAN}

\section{Hasil}

Pertama, karakteristik partisipan dalam penelitian ini rata-rata berusia 19 tahun $(S D=$ 1.23, Min=18, Max=25), mayoritas partisipan juga berusia 19 tahun (33.5\%) dan ikuti usia 20 tahun (28.1\%), 18 tahun (20.4\%), 21 tahun (13.2\%). Partisipan perempuan untuk penilitian ini lebih banyak, yaitu 121 partisipan $(72.5 \%)$ bila dibandingkan dengan partisipan pria yang hanya berjumlah 46 partisipan (27.5\%). Mayoritas partisipan merupakan angkatan 2017 sebanyak 56 partisipan (33.5\%). Partisipan mayoritas juga berada dari Fakultas Psikologi sebanyak 39 partisipan (23.4\%). Pada bagian tempat tinggal ada tiga tempat tinggal yang paling banyak ditinggali oleh partisipan, yaitu asrama, kos dan apartemen. Partisipan yang tinggal di asrama sebanyak 79 (47.3\%), kos 55 (32.9\%) dan apartemen 20 (12\%) partisipan.

Kedua, data di uji normalitasnya dan hasilnya dimensi anxiety ditemukan berdistribusi normal, karena nilai $p=.200$ dan itu berarti berada di atas standar yang adalah $p>.05$, namun dimensi avoidance, cognitive reappraisal dan expressive suppression persebaran datanya ditemukan tidak normal. Walaupun data didapatkan tidak berdistribusi normal, namun data ini masih bisa tetap dilanjutkan uji regresi. Hal ini karena data yang jumlahnya di atas 30 atau 40 masih bisa tetap melanjutkan uji regresi walaupun data tidak normal (Pallant; Field, dalam Ghasemi \& Zahediasl, 2012).

Ketiga, dilakukan uji korelasi antara adult attachment dan strategi regulasi emosi untuk melihat apakah terdapat hubungan yang signifikan, arah hubungan dan kekuatannya. Berdasarkan uji normalitas sebelumnya didapatkan bahwa data tidak berdistribusi normal sehingga uji korelasi akan menggunakan Spearman's Rho.

Hasil uji korelasi antara dimensi anxiety dengan cognitive reappraisal menunjukkan nilai koefisien korelasi sebesar $r=-.120, p=.121,(p>.01)$ dan uji korelasi antara dimensi anxiety dengan expressive suppression menunjukkan nilai koefisien korelasi sebesar $r=-.128$, $p=.098,(p>.01)$. Berdasarkan hasil tersebut bisa dilihat bahwa dimensi anxiety tidak memiliki korelasi yang signifikan dengan cognitive reappraisal maupun dengan expressive suppression.

Hasil uji korelasi antara dimensi avoidance dengan cognitive reappraisal menunjukkan nilai koefisien korelasi sebesar $r=-.051, p=.571,(p>.01)$, hasil menunjukkan bahwa tidak ada korelasi yang signifikan antara dimensi avoidance dengan cognitive reappraisal. Hubungan antara dimensi avoidance dengan expressive suppression $r_{s}=.334$, $p=.000,(p<.01)$, hasil ini menunjukkan adanya korelasi yang signifikan dengan kekuatan sedang antara dimensi avoidance dengan expressive suppression.

Keempat, dilakukan uji regresi berganda untuk melihat pengaruh adult attachment terhadap strategi regulasi emosi. 
Tabel 1. Hasil R Square Regresi Berganda

\begin{tabular}{|c|c|c|c|c|}
\hline Model & $\mathrm{R}$ & $\mathrm{R}^{2}$ & Adjusted $R^{2}$ & $\begin{array}{l}\text { Std. Error of } \\
\text { Estimate }\end{array}$ \\
\hline 1 & .367 & .135 & .124 & 4.60882 \\
\hline
\end{tabular}

a. Predictors: (Constant), TOTAL_AVOIDANCE, TOTAL ANXIETY

b. Dependent Variable: TOTAL_SUP

Tabel 2. Tabel Data ANOVA

\begin{tabular}{lclcll}
\hline Model & Sum of Squares & $\begin{array}{c}\text { Mean } \\
\text { Square }\end{array}$ & F & Sig. \\
\hline 1 & 541.374 & 270.687 & 12.743 & .000 & \\
& 3483.560 & 21.241 & & & \\
\hline
\end{tabular}

a. Dependent Variable: TOTAL_SUP

b. Predictors: (Constant), TOTAL_AVOIDANCE, TOTAL ANXIETY

Tabel 3. Koefisien Regresi Berganda

\begin{tabular}{lcccc}
\hline Model & $\mathrm{B}$ & $\begin{array}{c}\text { Beta } \\
(\beta)\end{array}$ & $\mathrm{t}$ & Sig. \\
\hline (Constant) & 5.836 & & 2.561 & .011 \\
Anxiety & .884 & .141 & 1.941 & .054 \\
Avoidance & 2.847 & .349 & 4.788 & .000 \\
\hline
\end{tabular}

a. Dependent Variable: TOTAL_SUP

Berdasarkan hasil tabel di atas bisa didapatkan persamaan regresi, yaitu:

$$
\mathrm{Y}=5.836+(.884) \mathrm{X}_{1}+(2.847) \mathrm{X}_{2}
$$

Persamaan regresi di atas menunjukkan bahwa jika skor dimensi anxiety dan avoidance adalah nol, maka skor expressive suppression akan sebesar 5.836. Jika terjadi penambahan satu skor pada dimensi anxiety, maka expressive suppression akan bertambah sebesar .884 dan jika penambahan satu skor dimensi avoidance, maka expressive suppression akan bertambah sebesar 2.847. Hasil dari tabel juga memperlihatkan bahwa nilai $F$ sebesar 12.743 dengan signifikansi sebesar .000 , hal ini menunjukkan bahwa variabel adult attachment dapat memengaruhi secara signifikan expressive suppression dan pengaruhnya sebesar $13.5 \%$ sedangkan sisanya $86.5 \%$ dipengaruhi oleh faktor lainnya.

Tabel 4. Hasil R Square Regresi Berganda

\begin{tabular}{|c|c|c|c|c|}
\hline Model & $\mathrm{R}$ & $\mathrm{R}^{2}$ & Adjusted $R^{2}$ & $\begin{array}{c}\text { Std. Error of } \\
\text { Estimate }\end{array}$ \\
\hline 1 & .367 & .135 & .124 & 4.60882 \\
\hline
\end{tabular}

a. Predictors: (Constant), TOTAL_AVOIDANCE, TOTAL ANXIETY

b. Dependent Variable: TOTAL_COG

Tabel 5. Tabel Data ANOVA

\begin{tabular}{lccccc}
\hline Model & Sum of Squares & $\begin{array}{c}\text { Mean } \\
\text { Square }\end{array}$ & F & Sig. \\
\hline 1 & 541.374 & 270.687 & 12.743 & .000 & \\
& 3483.560 & 21.241 & & & \\
\hline
\end{tabular}

a. Dependent Variable: TOTAL_COG

b. Predictors: (Constant), TOTAL_AVOIDANCE, TOTAL ANXIETY 
Tabel 6. Koefisien Regresi Berganda

\begin{tabular}{lcccc}
\hline Model & $\mathrm{B}$ & $\begin{array}{c}\text { Beta } \\
(\beta)\end{array}$ & $\mathrm{t}$ & Sig. \\
\hline (Constant) & 5.836 & & 2.561 & .011 \\
Anxiety & .884 & .141 & 1.941 & .054 \\
Avoidance & 2.847 & .349 & 4.788 & .000 \\
\hline
\end{tabular}

Berdasarkan tabel di atas, terdapat persamaan regresi bisa diperoleh, yaitu:

$$
Y=34.658+(-.597) X_{1}+(-.719) X_{2}
$$

Melalui persamaan tersebut dapat dilihat, jika skor dari dimensi anxiety dan avoidance adalah nol, maka cognitive reappraisal akan sebesar 34.658. Jika terjadi penambahan satu skor angka pada dimensi anxiety, maka cognitive reappraisal akan menurun sebesar .597 dan jika penambahan pada dimensi avoidance maka cognitive reappraisal akan menurun sebesar .719 .

Dari persamaan yang bisa didapatkan melalui uji regresi berganda adult attachment terhadap cognitive reappraisal, dapat dilihat bahwa nilai $\mathrm{F}$ sebesar 57.560 dengan nilai signifikansi .384 dan itu berarti variabel adult attachment tidak secara signifikan memengaruhi cognitive reappraisal.

Kelima, dilakukan analisis tambahan dengan uji beda dan uji korelasi data demografis dengan variabel penelitian.

Tabel 7. Uji Beda Fakultas dengan Variabel Penelitian

\begin{tabular}{|c|c|c|c|c|c|c|c|}
\hline \multirow[b]{2}{*}{ Dimensi } & \multirow[b]{2}{*}{ Sig. } & \multicolumn{6}{|c|}{ Mean Rank } \\
\hline & & $\begin{array}{l}\text { Psikologi } \\
(\mathrm{n}=39)\end{array}$ & $\begin{array}{l}\text { FISIP } \\
(\mathrm{n}=13)\end{array}$ & $\begin{array}{l}\text { FAST } \\
(\mathrm{n}=35)\end{array}$ & $\begin{array}{c}\text { Pendidikan } \\
\text { Guru } \\
(\mathrm{n}=32)\end{array}$ & $\begin{array}{c}\text { BS } \\
(n=20)\end{array}$ & $\begin{array}{c}\text { Pari- } \\
\text { wisata } \\
(\mathrm{n}=13)\end{array}$ \\
\hline Anxiety & .131 & 76.26 & 97.92 & 72.03 & 67.20 & 71.28 & 98.77 \\
\hline Avoidance & .434 & 72.23 & 82.54 & 82.17 & 72.38 & 88.48 & 59.73 \\
\hline $\begin{array}{l}\text { Cognitive } \\
\text { reappraisal }\end{array}$ & .195 & 78.54 & 58.19 & 71.56 & 71.11 & 93.83 & 88.62 \\
\hline $\begin{array}{l}\text { Expressive } \\
\text { Suppression }\end{array}$ & .004 & 63.91 & 83.77 & 80.96 & 60.95 & 92.53 & 108.62 \\
\hline
\end{tabular}

Hasil tabel di atas adalah hasil uji beda antara data demografis fakultas dengan variabel penelitian. Penulisan beberapa fakultas ditulis dalam singkatan, seperti, FISIP yaitu Fakultas Ilmu Sosial Ilmu Politik, FAST yaitu Fakultas Sains dan Teknologi, BS yaitu Business School. Data demografis berupa fakultas ini ditemukan perbedaan yang signifikan dengan dimensi expressive suppression $(F=17.537, p=.004)$, sedangkan dengan dimensi lainnya tidak ditemukan perbedaan yang signifikan. Setelah melakukan uji Kruskal Wallis kemudian dilanjutkan dengan uji post hoc menggunakan uji Dunn-Bonferroni dan ditemukan perbedaan signifikan pada Fakultas Pendidikan Guru dan Pariwisata dengan nilai $p=.001$, $p<.05$

Tabel 8. Uji Beda Jenis Kelamin dengan variabel penelitian

\begin{tabular}{lccc}
\hline \multirow{2}{*}{ Dimensi } & \multicolumn{2}{c}{ Mean Rank } \\
& $\begin{array}{c}\text { Sig. }(2- \\
\text { tailed })\end{array}$ & $\begin{array}{c}\text { Perempuan } \\
(\mathrm{n}=121)\end{array}$ & $\begin{array}{c}\text { Laki-Laki } \\
(\mathrm{n}=46)\end{array}$ \\
\hline Anxiety & .302 & 81.62 & 90.25 \\
Avoidance & .220 & 86.82 & 76.58 \\
Cognitive reappraisal & .916 & 84.24 & 83.36 \\
Expressive Suppression & .562 & 82.67 & 87.51 \\
\hline
\end{tabular}


Berdasarkan hasil tabel di atas, uji beda jenis kelamin dengan Mean-Whitney tidak ditemukan adanya perbedaan jenis kelamin dengan semua variabel penelitian. Pada dimensi attachment, anxiety dengan jenis kelamin $(U=2495, p=.302)$ dan avoidance dengan jenis kelamin $(U=2441, p=.220)$. Pada strategi regulasi emosi, cognitive reappraisal dengan jenis kelamin $(U=2753, p=.916)$ dan expressive suppression dengan jenis kelamin $(U=2621$, $p=.562)$.

Tabel 9. Korelasi IPK dengan variabel penelitian

\begin{tabular}{lcc}
\hline Dimensi & IPK & $p$ \\
\hline Anxiety & $-.217^{* *}$ & $\mathbf{. 0 0 5}$ \\
Avoidance & .079 & .311 \\
Cognitive reappraisal & -.074 & .345 \\
Expressive Suppression & -.145 & .062 \\
\hline
\end{tabular}

** Korelasi signifikan di tingkat .01

Hasil dari tabel menunjukkan bahwa IPK mempunyai korelasi yang signifikan dengan dimensi anxiety dan arahnya bersifat negatif $(r=-.217, p<.01)$ dan dimensi lainnya tidak ditemukan korelasinya dengan data demografis IPK. Jadi jika nilai dimensi anxiety semakin tinggi maka nilai IPK akan semakin rendah dan sebaliknya.

\section{Pembahasan}

Berdasarkan hasil analisis ditemukan pengaruh yang signifikan $(p=.000)$ dari dimensi anxiety dan avoidance secara bersama-sama terhadap strategi regulasi emosi expressive suppression sebesar $13.5 \%\left(\mathrm{R}^{2}=.135\right)$. Ketika dimensi anxiety dikontrol maka hanya dimensi avoidance yang memberikan pengaruh secara signifikan $(p=.000, p<.05)$ dan dimensi anxiety ditemukan tidak berpengaruh secara signifikan $(p=.054, p>.05)$ kepada expressive suppression. Hasil ini juga didukung dari penelitian sebelumnya juga yang menemukan adanya korelasi positif dengan kekuatan yang lebih besar antara dimensi avoidance dengan expressive suppression daripada dimensi anxiety dengan expressive suppression (Read, dkk., 2018).

Hal ini bisa dijelaskan dari internal working model. Dimensi avoidance berhubungan dengan model of other, yaitu cara individu memandang orang lain. Individu dengan dimensi avoidance yang akan memandang orang lain tidak dapat diandalkan, tidak dapat dipercaya dan cenderung akan menjauh hubungan yang dekat dengan orang lain (Mikulincer \& Shaver, 2007). Individu dengan dimensi avoidance juga mempunyai keterbukaan perasaan yang rendah dan cenderung untuk menyangkal emosi negatif yang dirasakan. Jadi, ketika mengalami emosi negatif individu akan cenderung untuk menyimpannya, tidak menceritakan atau meminta bantuan kepada orang lain dan cara meregulasi emosinya adalah memendamnya dan mencoba untuk tidak mempedulikan emosi negatif tersebut.

Dimensi anxiety tidak memberikan pengaruh kepada expressive suppression. Hal ini bisa dikarena oleh internal working model, dimensi anxiety dikaitkan dengan model of self, yaitu cara individu memandang dirinya sendiri, bisa itu secara positif maupun secara negatif. Expressive suppression adalah regulasi emosi yang muncul dan penggunaannya meningkat karena tidak adanya orang lain yang dianggap bisa mendukung (Tsai, Nguyen, Weiss, \& Lau, 2017). Tidak adanya kehadiran dan dukungan dari orang lain akhirnya membuat individu tidak bisa menunjukkan emosinya dan memilih mengatasi emosi negatif yang dialami dengan cara menghindarinya (Larsen et al., 2012).

Berdasarkan hal tersebut bisa dilihat bahwa expressive suppression bisa muncul karena adanya penilaian akan orang lain, apakah orang lain itu bisa ada dan bisa diandalkan. Hal ini tentunya lebih mendukung dimensi avoidance yang memang berkaitkan dengan model of other, yaitu bagaimana cara individu memandang orang lain. Sedangkan dimensi anxiety 
yang lebih kepada model of self tidak memberikan pengaruh karena dimensi anxiety lebih mengarah kepada bagaimana individu memandang dirinya sendiri.

Uji regresi berganda berikutnya dilakukan kepada dimensi anxiety dan dimensi avoidance terhadap cognitive reappraisal. Hasilnya tidak ada pengaruh yang signifikan $(p=.384, p>.05)$ dari kedua dimensi secara bersama-sama terhadap strategi regulasi emosi cognitive reappraisal. Jika dilihat dimensi avoidance dikontrol tidak ditemukan pengaruh dari dimensi anxiety terhadap cognitive reappraisal $(p=.292, p>.05)$ dan jika dimensi anxiety dikontrol juga tidak ditemukan pengaruh dari dimensi avoidance secara signifikan $(p=.332$, $p>.05)$.

Tidak ditemukannya pengaruh karena dimensi avoidance akan cenderung meregulasi emosi dengan cara menekan emosi dan dimensi anxiety akan cenderung meregulasi emosi dengan cara menunjukkan emosi secara intens (Szepsenwol \& Simpson, 2018). Individu yang menggunakan kedua regulasi seperti di atas lebih diuntungkan ketika berada dalam lingkungan yang mengancam dan tidak pasti (Szepsenwol \& Simpson, 2018).

Mahasiswa perantau yang berada di tempat perantauanya berarti harus menghadapi lingkungan baru. dan mulai mengeksplorasi lingkungan baru tersebut (Kural \& Ozyurt, 2018). Kural dan Ozyurt (2018) juga menyebutkan bahwa lingkungan baru mahasiswa perantau ini bisa disebut sebagai strange situation. Lingkungan baru ini bisa menjadi lingkungan yang tidak pasti dan tidak bisa diprediksi, karena mahasiswa perantau bisa saja menemukan perbedaan-perbedaan, hal-hal baru, masih membutuhkan waktu untuk beradaptasi dan berani mengungkapkan apa yang dirasakan.

Szepsenwol dan Simpson (2018) menyebutkan individu lebih diuntungkan dengan menggunakan regulasi emosi yang dysfunctional, seperti menekan emosi dan melebihlebihkan emosi ketika berada dalam lingkungan yang mengancam dan tidak pasti. Mahasiswa perantau karena juga berada di lingkungan yang tidak pasti di tempat perantauannya bisa lebih menggunakan kedua strategi regulasi emosi tersebut. Expressive suppression bisa membantu dalam mengalihkan emosi yang negatif dan hal ini bisa efektif ketika tidak adanya orang lain yang bisa mendukung (Szepsenwol \& Simpson, 2018). Melebih-lebihkan emosi negatif yang muncul bisa membantu mempercepat mencapai tujuan yang sifatnya short-term, terlebih lagi jika individu bisa mengabaikan efek panjang dari emosi negatif tersebut (Szepsenwol \& Simpson, 2018).

Berdasarkan hal di atas bisa dilihat bahwa adult attachment tidak memberikan pengaruh terhadap cognitive reappraisal karena melihat kondisi partisipan yang adalah mahasiswa perantau. Mahasiswa perantau berada di lingkungan yang tidak bisa diprediksi oleh mahasiswa perantau itu sendiri. Sehingga penggunaan strategi regulasi emosi expressive suppression dan dengan cara menunjukkan emosi secara intens ditemukan lebih memberikan keuntungan jika berada dilingkungan yang tidak pasti atau tidak bisa diprediksi (Szepsenwol \& Simpson, 2018).

Analisis tambahan lain menguji perbedaan antar fakultas dalam hal variable expressive suppression. Expressive suppression ditemukan berbeda secara signifikan pada Fakultas Pendidikan Guru dan Fakultas Pariwisata. Salah satu faktor yang bisa memengaruhi regulasi emosi adalah lingkungan sosial. Hal ini juga disebutkan oleh d'Arbeloff et al. (2018) bahwa konteks sosial memberikan pengaruh terhadap regulasi emosi. Pada penelitian ini regulasi emosi yang ditemukan memiliki perbedaan adalah strategi regulasi emosi expressive suppression. Tsai et al. (2017) menyebutkan bahwa penggunaan expressive suppression yang tinggi bisa disebabkan oleh lingkungan sosial, adanya penolakan secara sosial dan juga hubungan buruk dengan orang lain. Larsen et al. (2012) juga menyebutkan bahwa jika tidak dukungan dari orang lain, maka ketika individu mengalami emosi negatif atau hal yang tidak menyenangkan yang bisa dilakukan untuk mengatasi hal itu adalah menghindarinya. 
Jika melihat data demografis yang ada, mahasiswa perantau yang berasal dari Fakultas Pendidikan Guru akan tinggal di dalam asrama. Blimling (dalam Wijaya, 2016) menyebutkan mahasiswa yang tinggal di asrama akan menghabiskan waktunya lebih banyak bersama teman-teman di asrama. Shook dan Fazio (dalam Wijaya, 2016) juga menyebutkan bahwa tinggal di asrama bisa memungkinan mahasiswa untuk menjalin hubungan yang lebih dekat, karena adanya interaksi personal dan bisa membentuk pertemanan. Mahasiswa Fakultas Pendidikan Guru yang tinggal di asrama hidup bersama dalam satu kamar, melakukan kegiataan bersama dalam satu kamar, bahkan bisa memungkinan kembali bertemu di kelas yang sama ketika kuliah. Hal ini bisa memfasilitasi untuk bisa mempunyai lingkungan sosial dan dukungan dari orang lain. Oleh karena mahasiswa perantau Fakultas Pendidikan Guru mempunyai dukungan dari orang lain, maka kecenderungan untuk melakukan expressive suppression tidak akan tinggi.

Jika dibandingkan dengan mahasiswa perantau Fakultas Pariwisata yang tidak wajib untuk tinggal di asrama dan banyak yang tinggal sendiri, seperti di apartemen maupun kos. Hal ini bisa memperlihatkan perbedaan orang-orang yang tinggal bersama mahasiswa perantau. Kehadiran orang disekitar lebih mendukung penggunaan expressive suppression yang rendah karena Individu bisa menunjukkan emosinya pada orang-orang disekitarnya, dibandingkan tidak adanya orang disekitar yang mendukung hingga bisa meningkatkan penggunaan expressive suppression (Tsai et al., 2017).

Fakultas Pendidikan Guru karena mempunyai lingkungan dengan sistem asrama yang membuat mahasiswanya akan bersama dengan teman sekamarnya setiap hari dan hal ini lebih memungkinan mahasiswa untuk membangun hubungan dengan teman sekamar dan jika mengalami emosi negatif, mahasiswa bisa mengekspresikan emosi tersebut. Berdasarkan halhal di atas bisa dilihat bahwa memang memungkinan mahasiswa dari Fakultas Pendidikan Guru menggunakan expressive suppression yang lebih rendah jika dibandingkan dengan mahasiswa dari Fakultas Pariwisata.

Analisis tambahan lainnya menguji beda antara jenis kelamin dengan variabel penelitian dan tidak ada ditemukan perbedaan jenis kelamin pada adult attachment dan strategi regulasi emosi. Analisis selanjutnya melihat hubungan IPK dengan variabel penelitian dan ditemukan korelasi yang arahnya negatif antara IPK dan dimensi anxiety. Hal ini bisa dijelaskan karena individu dengan dimensi anxiety mempunyai pandangan yang buruk akan diri sendiri (Bartholomew dalam Otani, dkk., 2015). Individu akan merasa tidak berdaya, tidak mampu atau tidak kompeten dalam menghadapi suatu permasalahan (Read, dkk., 2018).

Salah satu permasalahan yang dihadapi oleh mahasiswa perantau berdasarkan survei yang sudah dilakukan dan menduduki masalah yang paling banyak dihadapi adalah masalah akademik. Jika mahasiswa perantau merasa bahwa diri tidak mampu maka ketika menghadapi permasalahan akademik mahasiswa perantau bisa tidak bersungguh-sungguh dalam hal akademik tersebut karena dari awal sudah merasa tidak mampu dan akhirnya berdampak pada IPK. Jika mahasiswa perantau mempunyai IPK yang tinggi maka hal itu menunjukkan bahwa mahasiswa mempunyai self-competence, yakin bahwa dirinya bisa dan hasilnya bisa dilihat dari IPK.

Kogut (2016) menyebutkan bahwa dimensi anxiety yang tinggi akan berkontribusi dalam membuat individu percaya bahwa sesuatu akan gagal dan itu bisa menyebabkan mahasiswa mudah menyerah dalam hal akademik dan menyebabkan rendahnya nilai IPK. Kurland \& Siegel (2013) menemukan dalam penelitiannya bahwa dimensi anxiety mempunyai hubungan yang negatif dengan nilai GPA mahasiswa tahun pertama. Penelitian lainnya yang juga dilakukan oleh Kurland \& Siegel (2013) juga menemukan bahwa ada hubungan yang negatif antara dimensi anxiety dengan GPA dan self-efficacy. Sehingga jika dimensi anxiety tinggi maka nilai GPA dan self-efficacy menjadi rendah. 


\section{KESIMPULAN DAN SARAN}

Pada bagian ini peneliti menuliskan beberapa saran teoritis dari hasil penelitian yang sudah dilakukan.

1. Penelitian selanjutnya bisa lebih memperhatikan pembuatan kuesioner, lebih baik kuesioner tidak dibuat secara bolak balik agar partisipan bisa mengisi semua kuesioner tanpa ada yang terlewat.

2. Penelitian selanjutnya apabila ingin memakai data demografis berupa suku, bisa mengelompokan suku agar partisipan bisa langsung memilih. Hal ini akan membantu mengontrol data suku sehingga tidak terlalu beragam dan nantinya bisa dianalisis.

3. Penelitian selanjutnya bisa mengambil jumlah sampel yang lebih proposional agar sampel yang dapat mewakili dan dapat dianalisis.

4. Penelitian selanjutnya bisa meneliti dengan variabel peer attachment, hal ini mempertimbangkan bahwa orang-orang yang akan lebih sering berada di lingkungan mahasiswa perantau adalah teman sebaya.

Pada bagian ini peneliti menuliskan beberapa saran praktis yang dapat bermanfaat bagi pihak lain yang membaca.

1. Kepada pihak universitas bisa memberikan materi atau kegiataan yang bisa meningkatkan pemakaian stratregi regulasi emosi cognitive reappraisal. Materi atau kegiatan bisa dibuat untuk semakin mengembangkan cara berpikir postformal thought yang nantinya bisa membantu mahasiswa untuk memakai cognitive reappraisal. Materi atau kegiatan ini bisa dalam bentuk seminar, workshop, atau bisa dimasukkan sebagai aktivitas di dalam kelas dan tugas untuk mahasiswa perantau.

2. Kepada mahasiswa perantau yang memiliki dimensi avoidance yang tinggi bisa belajar untuk mempercayai orang lain dan mengakui diri bahwa ada saatnya membutuhkan orang lain. Sehingga bisa mengurangi kecenderungan meregulasi emosi dengan cara yang memendam dan bisa mengembangkan regulasi emosi yang lebih adaptif, yaitu dengan tidak memendam, namun menerima dan mencoba melihat dari sisi yang berbeda.

\section{DAFTAR PUSTAKA}

Ahmetoglu, E., Ildiz, G. I., Acar, A., Ibrahim, H., \& Encinger, A. J. (2018). Children emotion regulation and attachment to parent: Parental emotion socialization as moderator. Social Behavior and Personality, 46(10), 1-16.

Anggraini, E. (2015). Strategi regulasi emosi dan perilaku koping religious narapidana wanita dalam masa pembinaan. Studi kasus: Lembaga pemasyarakatan wanita klas II A Bulu Semarang. Teologia, 26(2), 284-311.

Bartholomew, K., Kwong, M. J., \& Hart, S. D. (2001). Attachment. In W. J. Livesley (Ed.), Handbook of personality: Theory, research, and treatment (pp. 196-230). New York: The Guildford Press.

Ghasemi, A., \& Zahediasl, S. (2012). Normality tests for statistical analysis: A guide for nonstatisticians asghar. Int J Endocrinol Metab, 10(2),486-489.

Gravetter, F. J., \& Forzano, L. B. (2012). Research methods for behavioral sciences $\left(4^{\text {th }} \mathrm{ed}\right)$. Belmont, CA: Wadsworth. 
Gross, J. J., \& John, O. P. (2003). Individual differences in two emotion regulation processes: Implications for affect, relationships, and well-being. Journal of Personality and Social Psychology, 85(2), 348-362.

Hepper, E. G., \& Carnelley, K. B. (2012). Attachment and romantic relationships: The role of models of self and other. In M. Paludi (Ed.), The psychology of love (pp. 133-154). Santa Barbara, CA: Praeger.

Kamus Besar Bahasa Indonesia. (2008). Jakarta: Pusat Bahasa.

Kemenristekdikti. (2017). Statistik pendidikan tinggi tahun 2017. Jakarta: Pusat Data dan Informasi Iptek Dikti.

Kural, A. I., \& Ozyurt, B. E. (2018). The associations between university adjustment, adult attachment styles, personality traits, and perceived stress. American International Journal of Social Science, 7(2), 43-54.

Kurland, R. M., \& Siegel, H. I. (2013). Attachment and student success during the transition to college. Nacada Journal, 33(2), 16-28.

Kogut, E. (2016). Adult attachment styles, self-efficacy, and causal attributional style for achievement-related failures. Learning and Individual Differences, 50(2016), 64-72.

Larsen, J. K., Vermulst, A. A., Eisinga, R., English, T., Gross, J. J., Hofman, E., ... \& Engels, R. C. (2012). Social coping by masking? Parental support and peer victimization as mediators of the relationship between depressive symptoms and expressive suppression in adolescents. Journal of youth and adolescence, 41(12), 1628-1642.

Mikulincer, M., \& Shaver, P. R. (2007). Attachment in adulthood: Structure, dynamic, and change. New York: The Guildford Press.

Ong, E., \& Thompson, C. (2018). The important of coping and emotion regulation in the occurrence of suicidal behavior. Psychological reports, O(0), 1-19.

Otani, K., Suzuki, A., Matsumoto, Y., Enokido, M., Kuwahata, F., \& Takahashi, N. (2015). Associations of working model of the self and other with cloninger's personality dimensions. Comprehensive Psychiatry, 56, 175-178.

Pascuzzo, K., Moss, E., \& Cyr, C. (2015). Attachment and emotion regulation strategies in predicting adult psychopathology. Sage Open, 5(3), 1-15.

Perry, C. J. (2016). Comparing international and american students' challenges: A literature review. Journal of International Students, 6(3), 712-721

Read, D. L., Clark, G. I., Rock, A. J., \& Coventry, W. L. (2018). Adult attachment and social anxiety: The mediating role of emotion regulation strategies. PloS one, 13(12), 1-21.

Ridha, A. A. (2018). Task commitment pada mahasiswa suku bugis yang merantau. Jurnal Psikologi, 45(1), 66-76.

Rufaida, H., \& Kustanti, E. R. (2017). Hubungan antara dukungan sosial teman sebaya dengan penyesuaian diri pada mahasiswa rantau dari sumatera di universitas diponegoro. Jurnal Empati, 7(3), 217-222.

Szepsenwol, O., \& Simpson, J.A. (2018). Attachment within life history theory: An evolutionary perspective on individual difference in attachment. Copsyc, 25, 1-21.

Tsai, W., Nguyen, D. J., Weiss, B., Ngo, V., \& Lau, A. S. (2017). Cultural differences in the reciprocal relations between emotion suppression coping, depressive symptoms and interpersonal functioning among adolescents. Journal of abnormal child psychology, 45(4), 657-669.

Wijaya, F.A. (2016). Hubungan antara strategi regulasi emosi dan kelekatan dengan teman sebaya pada emerging adulthood yang tinggal di asrama. (Unpublished). Universitas Pelita Harapan, Indonesia. 